\title{
Projetos globais e resistências locais: pescadores artesanais e Unidades de Conservação no litoral, Rio de Janeiro - Brasil
}

\section{Global Projects and Local Resistances: Traditional Fishermen and Conservation Units at Coastal Rio de Janeiro - Brazil}

\author{
Monica Cox de Britto PEREIRA* \\ Yasmim Ribeiro MELLO**
}

\begin{abstract}
RESUMO
Este artigo aborda impasses em regiões litorâneas em torno de áreas protegidas e destino de população tradicional no Domínio da Mata Atlântica, Rio de Janeiro, Brasil. Existem resistências antigas por parte de pescadores tradicionais frente à especulação imobiliária. A política ambiental muitas vezes encontra-se referenciada no conceito de natureza intocada considerada virgem, da qual o ser humano não faz parte, tanto nas unidades de conservação de proteção integral como nas de uso sustentável. A Área de Proteção Ambiental de Maricá abriga, há três séculos, comunidade de pescadores artesanais. A implantação de um resort por um grupo luso-espanhol está em negociação pelo município e vem cerceando e ameaçando os pescadores locais. Impõe-se uma natureza mercadoria à venda para turistas em choque com uma natureza que por várias gerações foi concebida tendo como base a convivência, a reprodução familiar e a segurança alimentar. O Parque Estadual da Tiririca, Niterói, enfrenta dilemas para sua delimitação e garantia do direito da permanência de comunidade tradicional de pescadores no Morro das Andorinhas. Os casos pesquisados são, dentre inúmeros, exemplos de municípios com presença de comunidades vivendo da tradição da pesca e da agricultura que acabam sendo cerceados de suas atividades na terra. Transformações marcadas por expressiva desigualdade social e subalternização à lógica de dominação, a partir de uma visão reducionista que reforça a concepção de natureza virgem e a elitização dessas áreas verdes.
\end{abstract}

Palavras-chave: comunidades tradicionais; conflito socioambiental; Mata Atlântica; Rio de Janeiro.

\begin{abstract}
In this article we address impasses in coastal regions around protected areas and destinations of traditional population in the Atlantic Forest, Rio de Janeiro, Brazil. There has been some resistance from traditional fishermen against the real estate speculation. Environmental policies are founded on the concept of pristine virgin nature where human beings are not included, in both total protection and sustainable use conservation units. The Environmentally Protected Area of Marica lodges a three-century community
\end{abstract}

\footnotetext{
"Doutora em Ciências Sociais em Desenvolvimento, Agricultura e Sociedade pela Universidade Federal Rural do Rio de Janeiro (CPDA-UFRRJ). Professora adjunta do Depto. de Ciências Geográficas - UFPE, POSGEO-UFF, PRODEMA-UFPE. Email: monicacox@ig.com.br

** Geógrafa UFF e Mestre em Engenharia Civil pela UFRJ/COPPE. Email: yasmimribeiro@yahoo.com.br
} 
of traditional fishermen. The establishment of a resort is being negotiated by the city council and has been restricting and threatening local fishermen. Nature as merchandise is imposed for sale to tourists as opposed to nature conceived as cohabitation, family reproduction and food security. The State Park Tiririca, in Niterói, faces dilemmas regarding its delimitation and residential rights guarantee of the traditional fishermen community in Morro das Andorinhas. The negative impacts of coastal activities are countless, as well as projects in municipalities with the presence of local communities living in the tradition of fishing and agriculture who are expelled from the land. Changes are marked by significant social inequality and subordination to the logic of domination, from the reductionist view that reinforces the concept of virgin nature and the gentrification of these green areas.

Key-words: traditional communities; environmental conflict; Atlantic rainforest; Rio de Janeiro.

\section{Introdução}

Ao longo do litoral do Rio de Janeiro (Brasil), existem resistências antigas por parte de pescadores artesanais frente à crescente ocupação das áreas costeiras para especulação imobiliária, loteamentos e empreendimentos turísticos. A política ambiental encontra-se enraizada em um conceito de natureza que pressupõe uma natureza dicotomizada do ser humano, uma natureza intocada sem gente e que, por conseguinte, leva a uma lógica de intervenções tendo como eixo a redução dos "obstáculos" naturais, bem como a artificialização desses ambientes.

São inúmeros os impactos negativos e conflitos gerados por atividades e projetos ao longo do litoral, sobretudo naqueles municípios que ainda apresentam marcada presença de comunidades tradicionais vivendo da pesca e da agricultura. Little (2002) aponta alguns elementos centrais na conceituação de populações tradicionais: "existência de regimes de propriedade comum, o sentido de pertencimento a um lugar, a procura de autonomia cultural e práticas adaptativas sustentáveis que variados grupos sociais mostram na atualidade"1 (LITTLE, 2002, p. 23). Estas populações acabam quase sempre tendo seu lugar ocupado por grandes condomínios de luxo, hotéis, resorts e toda a rede de serviços que envolvem a atividade turística nacional e internacional. Esses empreendimentos provocam a expulsão de pescadores, agricultores, indígenas, ameaçando a pesca artesanal. Além disso, vários resorts são construídos em áreas de preservação ambiental e provocam impactos nos âmbitos social e ecológico. Tais aspectos foram bem retratados por Meirelles (2006) na região costeira do Ceará, bem como por Limonad (2007) na costa da Bahia. Essas populações não são absorvidas como mão de obra, contrariando a ideia de que planejamentos desta ordem são importantes para o aumento do número de empregos na região. Durante o período de obras pode-se dizer que isto ocorra, no entanto, aqueles que trabalharão nas grandes redes de hotéis e resorts são oriundos de outras regiões, visto que a demanda é por mão de obra qualificada. Em última análise, esse contexto gera o aumento da segregação socioespacial nestes municípios. Limonad (2007), em pesquisa abordando os resorts da costa verde na Bahia, ressaltou que, em nome do desenvolvimento local sustentável, da geração de empregos e da inserção nos fluxos produtivos, vários municípios abrem exceções ou encontram soluções para compromissos com grupos imobiliários, hoteleiros e turísticos de porte internacional. Assim, ocorre uma expansão indiscriminada de atividades de turismo e veraneio, que colocam em risco os ecossistemas costeiros tropicais.

A heterogeneidade dos ecossistemas litorâneos do Domínio da Mata Atlântica abrange remanescentes de matas, restingas, dunas, brejos, lagoas ferruginosas de águas escuras, manguezais e recifes de coral. Abrigam grande diversidade de espécies vegetais e animais e constituem habitats reprodutivos, os quais reforçam a ideia da necessidade de preservação ambiental. Tais orientações, atividades e projetos ocorrem a partir de um discurso pela ação da revitalização do ambiente, levando a noção de que somente a partir de tal intervenção será possível preservar

\footnotetext{
${ }^{1}$ Little (2002) ressalta que ocorreram muitos embates na tramitação do projeto de lei do Sistema Nacional de Unidades de Conservação (Lei n ${ }^{9.985 / 2000)}$ entre as vertentes preservacionista e socioambientalista do movimento ambientalista em torno dos conflitos de populações em áreas protegidas, sendo uma das cláusulas mais discutidas a definição da categoria de "população tradicional" e, como não houve acordo entre as partes, a cláusula foi vetada do texto final da lei: "O vetado inciso XV do Artigo $2^{\circ}$ do Capítulo lia: grupos humanos culturalmente diferenciados, vivendo há no mínimo três gerações em um determinado ecossistema, historicamente reproduzindo seu modo de vida, em estreita dependência do meio natural para sua subsistência e utilizando os recursos naturais de forma sustentável." (LITTLE, 2002, p. 17).
} 
a natureza - sem tocar, somente apreciar, concepção esta veiculada como garantia de preservação. A fim de tornar este discurso verdadeiro, utiliza-se do ecoturismo como ferramenta-chave e de toda a rede que ali será e é implementada: especulação imobiliária, afastamento das populações locais tradicionais e turismo acelerado.

Importante distinguir as concepções de preservação e de conservação ambiental, conforme abordado em Diegues (1996). A preservação ambiental é uma concepção que tem predominado no debate ambiental, que entende preservação referenciando-se na existência de uma natureza intocada, sem a presença humana. Por outro lado, a concepção de conservação ambiental pressupõe a possibilidade do uso da natureza num horizonte de sustentabilidade, na qual a conservação inclui a presença humana em convivência com a natureza.

$\mathrm{O}$ ordenamento territorial e ambiental das áreas litorâneas de mata e restinga serão aqui analisados, bem como a relação entre conservação ambiental e populações tradicionais. $\mathrm{O}$ estudo em tela foi conduzido tendo como eixo o tripé ensino-pesquisa-extensão ${ }^{2}$ e como base metodológica o diálogo de saberes (MELLO; PEREIRA, 2008). Analisaram-se impasses em torno da criação de áreas protegidas e o destino de populações tradicionais moradoras de áreas costeiras no Domínio de Mata Atlântica, bem como conflitos em áreas protegidas criadas a partir da década de 1980, envolvendo pescadores em área de Parque - Comunidade de Andorinhas \& Parque Estadual da Tiririca (1992) - e em Área de Preservação Ambiental - Comunidade de Zacarias \& APA Maricá (1984). Com base em Diegues e Arruda $(2001)^{3}$, consideramos o conceito de população tradicional referenciando-se naqueles que vivem em áreas geográficas particulares e demonstram, em vários graus, características tais como: ligação intensa com os territórios ancestrais; autoidentificação e reconhecimento pelos outros povos como grupos culturais distintos; presença de instituições sociais e políticas próprias e tradicionais; e sistemas de produção voltados principalmente para a subsistência. Ressaltamos que, como população local, entendemos que estão incluídos todos os moradores daquele lugar.

\section{Comunidade de Pescadores Artesanais do Morro das Andorinhas}

No município de Niterói, RJ, o Parque Estadual da Tiririca foi criado no ano de 1992 (SIMON, 2003). Existe uma série de questões que vêm sendo enfrentadas na delimitação da área do parque e na presença de comunidade secular tradicional de pescadores no Morro das Andorinhas, situado na Serra da Tiririca (Domínio da Mata Atlântica). Dentre elas, destaca-se: o que fazer com a população de pescadores artesanais que reside no entorno do parque? Será retirada ou incluída no parque sob restrições, e que restrições serão aplicadas nestas condições?

\section{Histórico}

O Morro das Andorinhas localiza-se em zona urbana, na região costeira da cidade de Niterói-RJ, composta por praias, lagunas, vegetação de restinga e Mata Atlântica, entre os bairros de Itacoatiara e Itaipu, considerados área nobre da cidade. São bairros de classe média alta, com condomínios e casas localizados no entorno do parque, fruto de expansão urbana nas últimas décadas. Entretanto, em Itaipu há um processo de resistência por parte de comunidade tradicional de pescadores - a Comunidade de Andorinhas (Fig. 1).

O Morro das Andorinhas está situado dentro de uma área considerada um dos últimos pontos de conservação da Mata Atlântica, em Niterói, o que o torna área importante nos limites do Parque Estadual da Serra da Tiririca, bem como é reconhecido pelo Plano Diretor do município, aprovado em 1992, como Área de Preservação Permanente. Com base no Sistema Nacional de Unidades de Conservação (SNUC, 2002), a categoria Parque é uma unidade de conservação de proteção integral, restritiva, que não permite a permanência de populações residindo em seu interior. O Código Florestal (Lei no 4.771/1965) reforça a área como de preservação, visto que considera algumas áreas como de preservação permanente.

\footnotetext{
${ }^{2}$ A autora vem enfocando em suas atividades acadêmicas de pesquisa a importância do diálogo de saberes na construção do conhecimento. Desta forma, a pesquisa se desenvolveu tendo metodologicamente como etapas iniciais o contato com as comunidades por meio de trabalhos de campo com a graduação (disciplinas - Ecologia e Agroecologia), valorizando-se o diálogo com as comunidades e a escuta das histórias de vida. Em outros momentos, por meio de projeto de extensão, contamos com a participação destes em evento acadêmico e trocas na universidade (Semana de Agroecologia UFF).

${ }^{3}$ Consultar Diegues e Arruda (2001, p. 23-31).
} 


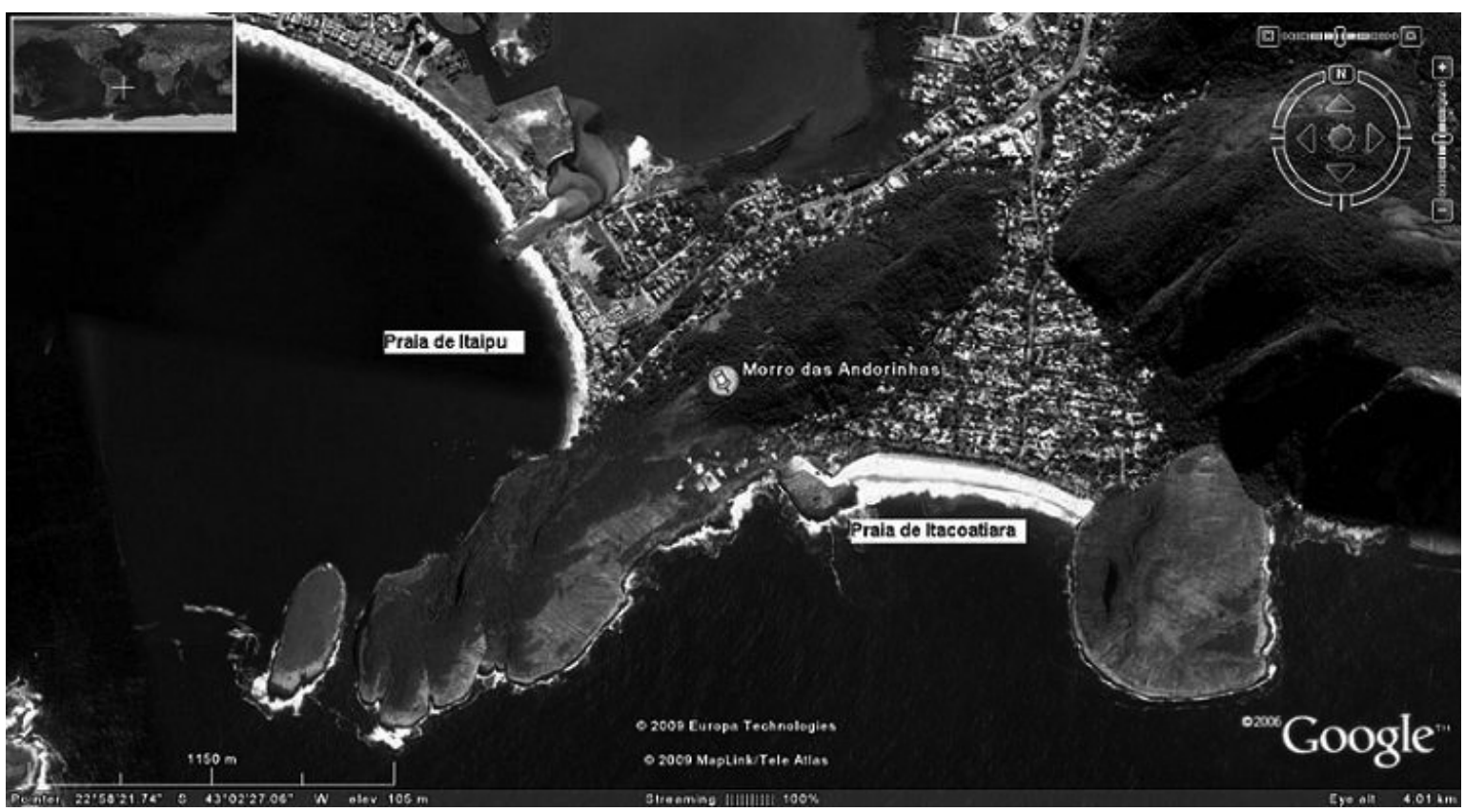

FIGURA 1 - LOCALIZAÇÃO DA COMUNIDADE DE ANDORINHAS, MORRO DAS ANDORINHAS, SERRA DA TIRIRICA (RIO DE JANEIRO, BRASIL).

FONTE: Google Earth, elaborado pelas autoras.

O topo do Morro das Andorinhas abriga aproximadamente uma população de 37 pessoas, todas ligadas direta ou indiretamente a atividades de pesca e que remontam ao final do século XIX (MOTA, 2007; LEITE, 2003). Além da pesca, também há presença de atividades de manutenção da subsistência na terra: plantam e manejam algumas ervas medicinais, café, leguminosas e frutas. Entretanto, esta prática da agricultura hoje é muito limitada, visto que a natureza ali é concebida como natureza intocada, o que vem restringindo as práticas agrícolas tradicionais. As famílias mais recentemente se constituíram como associação, denominada “Associação da Comunidade Tradicional do Morro das Andorinhas" (Fig. 2). Essa entidade vem se fortalecendo enquanto associação tradicional, conforme sinalizou Lobão (2007), como estratégia da luta para manter as famílias vivendo em seu lugar de origem. O reconhecimento do direito de acesso e uso do território no Morro das Andorinhas está em questão sob as dimensões política e jurídica.

Os moradores no Morro das Andorinhas se distribuem em 14 casas, de alvenaria e algumas de pau a pique. Têm sido alvo de conflitos na região. Mota (2007) chama

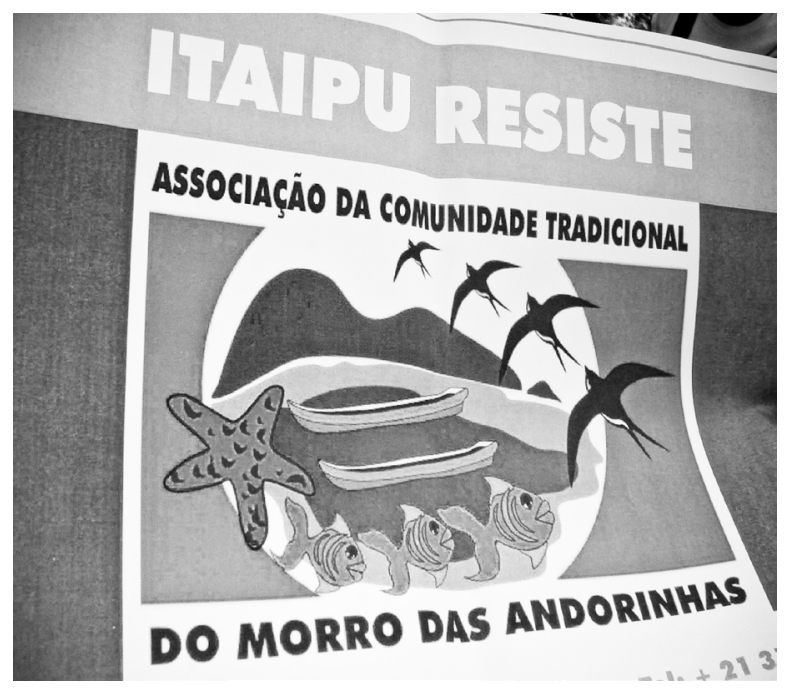

FIGURA 2 - ASSOCIAÇÃO DA COMUNIDADE TRADICIONAL DO MORRO DAS ANDORINHAS, SERRA DA TIRIRICA, ITAIPU, NITERÓI/RJ.

Foto: Mônica Cox, 2008. 
atenção que são considerados ameaça ao estético e, logo, uma ameaça à conservação ambiental, ao mesmo tempo em que fazem limite com os altos muros dos condomínios fechados, de onde se pode visualizar as mansões que se perdem por entre a praia e a Mata Atlântica. Isso também faz a elite dos condomínios sentir-se ameaçada por uma possível favelização e insegurança de seus bens. Como aqueles são pessoas de baixa renda, mesmo que antigas no local são interpretadas no bojo de um processo mais recente de migração para áreas de periferia; assim, suas ocupações territoriais são consideradas equivocadamente favelização.

Os constantes mecanismos econômicos, jurídicos e o uso da violência física pressionaram e ainda vêm pressionando muitos dos habitantes do local a migrarem para outros bairros da região, deslocando-se em sua maioria para áreas afastadas do ambiente costeiro. Esses aspectos vêm caracterizar ameaça à perda da identidade, visto que buscam outros modos de vida, que não a pesca. A população residente e resistente do Morro das Andorinhas ainda é alvo de pressões e interesses dos setores imobiliários, grupos do Estado e do Governo Municipal, membros de ONGs, ambientalistas e por moradores de classe média no entorno do Parque. O Ministério Público Estadual moveu uma Ação Civil Pública contra a Prefeitura de Niterói exigindo a desocupação da área, sob alegação de "danos ambientais e favelização" (LOBÃO, 2007, p. 130).

O Ministério Público tem a posição favorável à preservação ambiental e acaba por anular o ser humano como agente e parte integrante da natureza. Como resposta, a Secretaria Municipal de Urbanismo e Meio Ambiente de Niterói, após vistoria, expõe em relatório que se tratava "de mais um típico processo de favelização", considerando como "mais um exemplo real dos efeitos da crise social das regiões metropolitanas brasileiras sobre as áreas florestais remanescentes" (MOTA, 2009, p. 160). Como episódio emblemático desse conflito, deu-se a demolição de uma casa centenária do morador mais antigo, localizada no topo do morro, visto que passaram a ser interpretados como invasores e não como ocupantes antigos (MENDES; SARAIVA, 2001; MOTA, 2004).

Esses procedimentos demonstram claramente uma ameaça à permanência de populações tradicionais centenárias. Onde se situa a região de maior extensão da Mata Atlântica do município, a população é declaradamente encarada como uma ameaça e um potencial de degradação ambiental. Há diante deste comportamento um grave paradoxo, pois há mais de século esses atores sociais moram no local, conservando e garantindo à Mata Atlântica o status de conservação, tendo sido a presença dessa população fator-chave que evitou que a área fosse invadida, seja por migração de populações de baixa renda, seja por especulação imobiliária de condomínios. Numa sociedade urbano-industrial, torna-se invisibilizado que as áreas mais conservadas são aquelas onde há o manejo e a relação integrada dessas populações tradicionais com o meio e a natureza ali presente (DIEGUES, 2004; CASTRO, 2000; GOMÉZ-POMPA; KAUZ, 2000; POSEY, 1983).

Diante de tal problemática, medidas vêm sendo discutidas e os conflitos não cessam. Concebe-se desde a retirada total dessa comunidade até propostas que permitam a permanência das mesmas. Mas as exceções da expulsão das populações tradicionais são na prática uma forma de expulsão delas de seu território, visto que novas regras serão impostas, como, por exemplo, a não permissão de reprodução social, a não utilização da terra para subsistência e manejo agroflorestal e até a não permanência de um cão, visto que este não é caracterizado como tradicional. Sendo assim, direitos sobre seus modos de vida, acesso e apropriação estão sendo negados a tais populações. Destaca-se que esses grupos tradicionais em sua organização social priorizam em muito a diversidade da vida, como bem sinaliza Boff(1995):

As sociedades sempre organizam suas relações para com o meio no sentido de garantir a produção e reprodução da vida. [...] O ser humano é também e principalmente um ser de comunicação e de responsabilidade. Então ético seria também potenciar a solidariedade generacional no sentido de respeitar o futuro daqueles que ainda não nasceram. E por fim ético seria reconhecer o caráter de autonomia relativa dos seres; eles também têm direito de continuar a existir e coexistir conosco e com outros seres, já que existiram antes de nós e por milhões de anos sem nós. Numa palavra, eles têm direito ao presente e ao futuro (BOFF, 1995, p. 24).

Os fatos aqui analisados levam a refletir sobre a perspectiva da relação natureza-sociedade. Assim, destaca-se a importância da discussão para o eixo metodológico do diálogo entre conhecimento científico e conhecimento tradicional e da interação entre diferentes atores sociais. Diegues (1996; 2000) e Diegues e Arruda (2001) vêm desenvolvendo pesquisas que embasam a importância do etnoconhecimento e da etnoconservação, destacando que conservação pressupõe a participação das comunidades 
tradicionais. Esse autor define claramente o conhecimento a partir da tradição:

Conhecimento tradicional pode ser definido como o saber e o saber-fazer, a respeito do mundo natural e sobrenatural, gerados no âmbito da sociedade não urbano/industrial e transmitidos oralmente de geração em geração (DIEGUES, 2000, p. 30).

É importante destacar que essas populações estão "na e com a natureza", elas se mantêm em uma relação orgânica, diferente daquela proposta como natureza selvagem, intocada, sinônimo de natureza preservada, como é o caso dos parques e mesmo de unidades de conservação de uso sustentável. Diegues (2000) descreve etnobiodiversidade: a riqueza da natureza na qual participam os seres humanos, nomeando-a, classificando-a, domesticando-a, manejando-a. Entretanto, de nenhuma maneira nomeando-a selvagem e intocada, mesmo que essa natureza se apresente na maioria das vezes num status de conservação primária com alta biodiversidade e dinâmica ecológica conservada. Sobretudo, chama-se atenção para o equívoco que pode daí se desdobrar, considerando como uma natureza virgem e desabitada.

\section{Comunidade de Pescadores Artesanais de Zacarias}

Em 1984 foi criada a Área de Proteção Ambiental de Maricá, que inclui em seus limites a Comunidade de Zacarias - pescadores artesanais de lagoa, comunidade antiga de três séculos localizada na Restinga de Maricá, às margens da lagoa de Maricá. A restinga é formada por dois cordões arenosos entre o mar e a lagoa de Maricá, no Domínio da Mata Atlântica. A área é bem conservada, sendo parte do ecossistema de restinga com registro de grande biodiversidade (PEREIRA et al., 1989). A área vem sendo negociada pelo município para implantação de resort turístico. As atividades previstas abrangem piers, marinas, cais e conjuntos residenciais, a serem construídos sobre a área, o que vem ameaçando mais uma vez a permanência da comunidade no local, bem como causando cerceamento de suas atividades de trabalho e de sociabilidade.

O controle da circulação na área, por um lado, limita $\mathrm{o}$ acesso dos pescadores à restinga e, por outro, favorece $\mathrm{o}$ acesso de turistas. A restinga passa a ser incorporada como uma mercadoria à venda para turistas, em um claro descompasso para com o acesso à restinga como parte do território dos moradores locais. Estão em conflito duas concepções: uma natureza "selvagem" de aventura? Ou uma natureza da convivência, da reprodução familiar e da segurança alimentar? Retira-se a comunidade para preservar o verde? Ou garante-se a permanência da mesma sob restrições e ameaças à cultura da pesca e do território de séculos, bem como da própria restinga? É introduzida uma dicotomia entre as pessoas e a natureza, o que não fazia parte da vida das pessoas dessa comunidade.

\section{Histórico}

A cerca de $30 \mathrm{~km}$ do Rio de Janeiro, próximo ao epicentro da Região Metropolitana, está localizado o povoado de pescadores artesanais de Zacarias (Fig. 3), que remonta pelo menos ao século XVIII (MELLO; VOGEL, 2004).

O povoado de Zacarias ocupa área inclusa na Área de Proteção Ambiental Maricá, área da antiga Fazenda São Bento da Lagoa, Maricá, no Rio de Janeiro. Os pescadores estão organizados na Associação de Pescadores de Zacarias - ACCAPLEZ (Fig. 4). A região caracteriza-se por cordão arenoso litorâneo (dunas) entre laguna e mar, formado por vegetação e fauna de restinga. Há mais de três séculos convivem os pescadores com o encontro das águas da lagoa e do mar que, conforme Mello e Vogel (2004, p. 330): "estiveram sempre de acordo em denominar barra nativa o canal que punha em contato, periodicamente, a lagoa e o mar". Vêm resistindo a inúmeras intervenções, como a abertura permanente da barra via Canal de Ponta Negra, especulação imobiliária, mortandade de peixes e empreendimentos turísticos.

O manejo do ecossistema foi realizado pelas comunidades por meio de relação profunda de conhecimentos e convivência entre sociedade-natureza nesse sistema lagoa-mar até o ano de 1951. Os pescadores se remetem à existência dessa barras desde o "princípio do mundo" (MELLO; VOGEL, 2004, p. 331). A abertura da barra possibilitava a troca de nutrientes e matéria orgânica no ambiente, a diversidade de espécies de peixes, moluscos e crustáceos (camarões, p. ex.) e a garantia da piscosidade do sistema e da subsistência das comunidades pesqueiras. Era celebrada como um acasalamento do mar com a lagoa. "Com a barra, a lagoa transformava-se não só em nutriz de farta criação, e graças a esta, numa generosa fonte de 


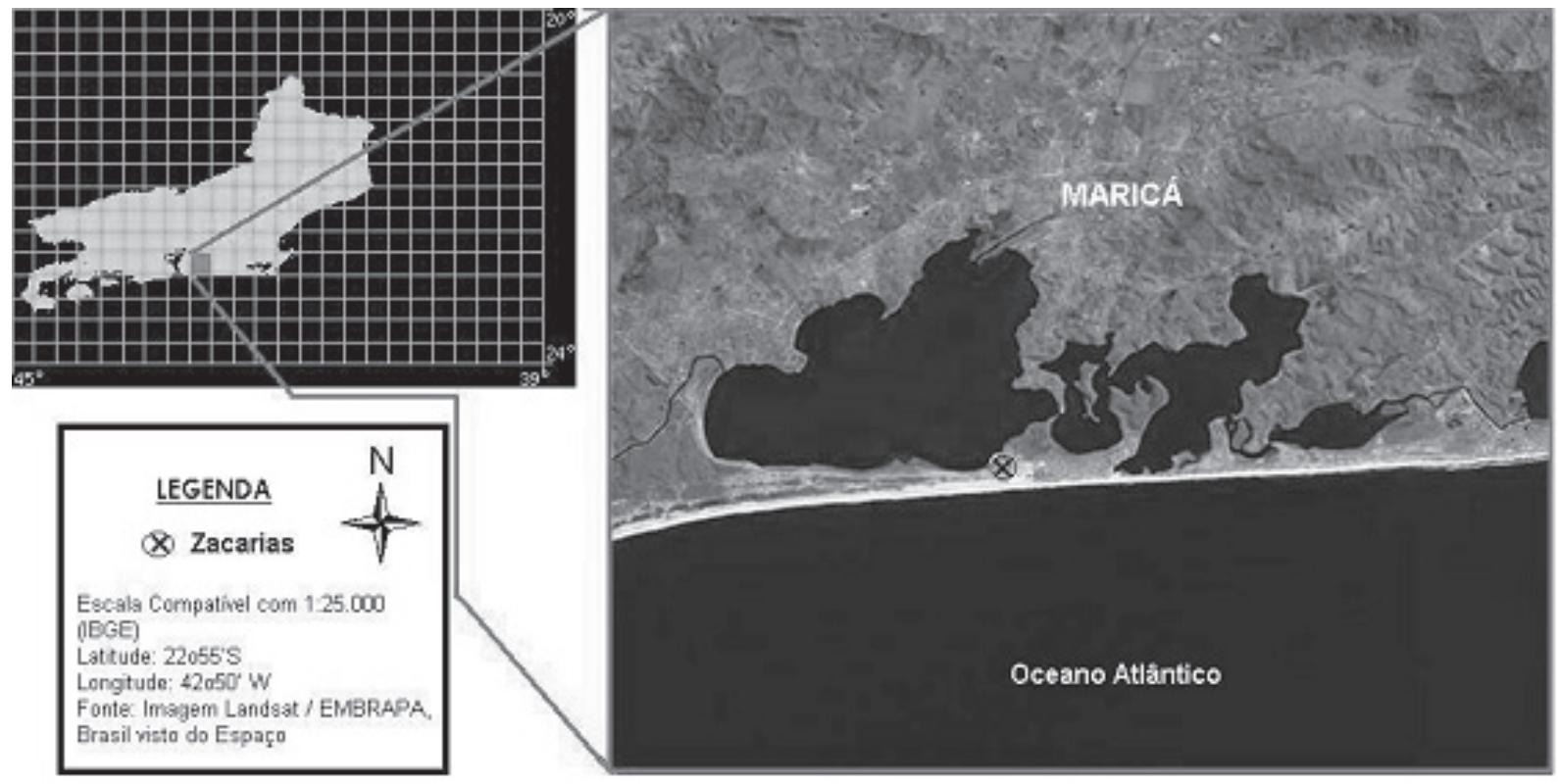

FIGURA 3 - LOCALIZAÇÃO DA COMUNIDADE DE ZACARIAS NAS PROXIMIDADES DA RESTINGA DE MARICÁ, ÀS MARGENS DA LAGOA (RIO DE JANEIRO, BRASIL).

FONTE: Landsat/Embrapa "Brasil Visto do Espaço", elaborado pelas autoras.

alimento para os pescadores. 'Essa barra aqui já criou para mais de trezentas famílias, só com a tarrafa!', recordava Ginho (MELLO; VOGEL, 2004, p. 347).

Os pescadores acompanhavam as constantes cheias da bacia hidrográfica, composta por cerca de vinte e um rios e córregos ao longo das seis lagunas (originadas por altos índices pluviométricos e variações da maré), que acarretavam em alguns casos grandes alagamentos e prejuízos para a pesca e às formas de vida de subsistência daquelas comunidades. Diante disso, os pescadores sabiam a importância da construção de uma abertura da barra, ligando a lagoa de Maricá ao mar. Mello e Vogel (1994) demonstram a maestria dos pescadores na intervenção citada quando entravam em cena os mestres-de-marca:

Decidida a oportunidade e convocados os participantes, entravam em cena os riscadores ou mestres-de-marca. Estes eram, invariavelmente, de Barra de Maricá, e respondiam pelo traçado da barra, de acordo com um saber que, não sendo esotérico, passava, no entanto, de pai para filho, dentro de algumas poucas famílias, às quais conferia autoridade e prestígio (MELLO; VOGEL, 1999, p. 12).
O manejo pelos pescadores se dava em consonância e convivência com a própria dinâmica lagoa e mar. Mello e Vogel (2004) apontam alguns aspectos desse trabalho das comunidades em conjunto com o da natureza na abertura da barra da lagoa:

Para chegar ao risco mais adequado, o mestre tem de levar em conta, além da época e das marés, a direção dos ventos e das correntes marítimas junto à costa. Tem, ainda, de levar em conta os prognósticos relativos ao tempo, a possibilidade de eventuais mudanças, prenunciadas na temperatura e cor da água, bem como na formação das nuvens. Com base em tudo isso, tem de escolher o ponto exato de ruptura do cordão arenoso e, finalmente, determinar e demarcar o risco da barra. $[\ldots]$

O risco da barra configura um triângulo, cuja base está na beirada da lagoa e cujo ápice encontra-se voltado para o mar, sobre a costeira. Esse triângulo é dividido em três seções: a caixa d'água, junto à lagoa; a cabeça grande, no meio; e o sangradouro, junto ao mar. O trabalho é executado por três turmas e consiste na escavação dessas três seções, até que o chão de cada uma delas alcance o 


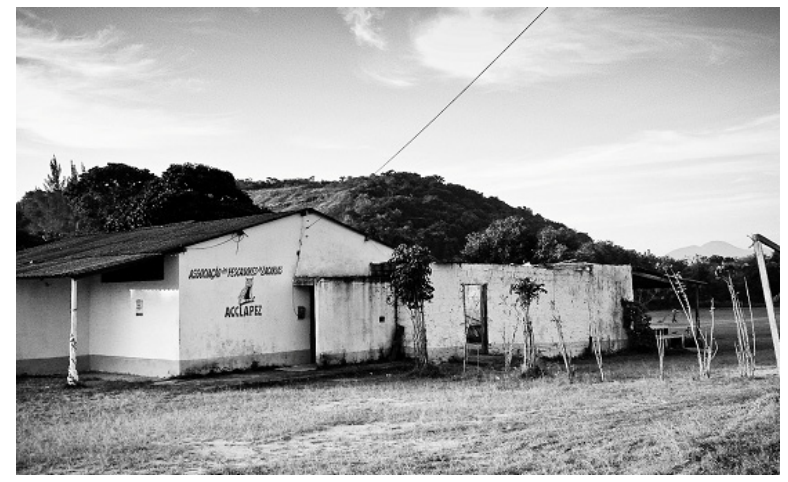

FIGURA 4 - ASSOCIAÇÃO DE PESCADORES DE ZACARIAS, RESTINGA DE MARICÁ, RJ.

Foto: Yasmim Mello, 2008.

nível do mar e da lagoa. [...] Concluída essa tarefa, os bancos são rompidos, um após o outro. Primeiro, corta-se aquele que separa a caixa d'água da lagoa. Quando esta tiver inundado o cômodo inteiro, rompe-se a comunicação com a cabeça grande. Por fim, corta-se o banco de areia que separa esta do sangradouro.

De resto encarrega-se a própria força da lagoa, escavando o que restava do cordão litorâneo, até começar a verter-se, com ímpeto, no mar. Desse ponto em diante, a barra toma carreira e vaza, ininterruptamente, durante três dias e três noites. Depois, prevalecem as marés. $\mathrm{Na}$ preamar, as águas do oceano rolam lagoa adentro, formando uma turbulência à qual os pescadores dão o nome de cavaleiros e que aprofunda, ainda mais, o canal. $\mathrm{Na}$ baixa-mar, a lagoa volta a correr para o oceano. Nesse regime a lagoa deve permanecer de 20 a 30 dias, para cumprir sua função. Em seguida, costumava fechar-se, graças ao dinamismo construtivo do mar (MELLO; VOGEL, 2004, p. 342, grifos do autor).

Ressaltam também os autores que existe o aspecto da celebração envolvida no trabalho de abertura da barra da lagoa para o mar:

O mar é o pai. A lagoa é a mãe. Quando uma barra toma carreira, é a mãe que se abre ao pai. E depois disso, "eles namoram, ficam regulando - uma hora ela sai, outra hora ele entra". E, assim, tanto ela "vai buscar a criação lá fora", quanto ele "vai botando a criação pra dentro". E ela vai ficando "cheia de vida". Para a criação vingar, entretanto, "ela precisa ficar de resguardo" (MELLO; VOGEL, 2004, p. 346).
Esse fato demonstra a força do conhecimento tradicional da comunidade de pescadores de Zacarias. A abertura da barra acompanhava o ritmo das marés, das luas e de alguns meses específicos, de acordo com o próprio conhecimento dos pescadores, para que assim pudesse coincidir com a desova do camarão e a corrida da tainha. A barra, enquanto permanecia aberta, era acompanhada de uma vigília permanente e se aplicavam várias interdições a fim de perpetuar a dinâmica do ecossistema e seus ciclos ecológicos, a partir das muitas observações e conhecimentos passados de geração em geração: não era permitido tarrafear, nem no canal, nem na boca da barra, assim como o trânsito de canoas ficava restrito a poucas travessias (MELLO; VOGEL, 2004).

No entanto, em fins dos anos 1940 e início dos anos 1950, as intervenções externas neste ambiente já começam a tomar expressão. Estas aberturas da barra nativa, celebradas com festas na restinga, foram interrompidas pelos projetos de Saneamento do Governo na região, que deu origem em 1951 ao Canal de Ponta Negra (BRAGA, 1947; MELLO; VOGEL, 2004).

Mello e Vogel (1999, p. 88) em depoimento de um dos pescadores, registraram que: "o mar não chegava mais a Maricá!". Isso significava que as águas oceânicas provenientes da Ponta Negra não conseguiam alcançar a Lagoa de Maricá e significava também que a fauna marítima não conseguia abrir caminho até chegar à Lagoa. Assim, tornaram-se excluídas do sistema diversas espécies marinhas, dentre estas o camarão. Isto trouxe um grande impacto àquele ambiente que constantemente se renovava e que, desde então, a água passou a não alcançar mais os ambientes lacustres e, sobretudo, não trouxe a renovação da vida, tanto para a fauna e flora como para aquelas populações que ali se distribuíam. Aconteceram episódios de enorme mortandade de peixes, visto que as espécies não conseguiam chegar à lagoa nem tampouco retornar ao mar.

A partir da década de 1950, esses pescadores se veem pressionados pelo discurso desenvolvimentista, bem como pelos planejamentos de desenvolvimento urbano que se seguiram no litoral fluminense. A lagoa e a restinga começam a ser valorizadas para lazer:

Desaparece totalmente a vegetação de restinga, aparecem as ruas de terra vermelha no meio da areia branquíssima e já dezenas de casas de veraneio com garages onde rebrilham lindos Cadillacs que vêm cada um com três ou quatro caniços envernizadíssimos, de lado do automóvel, para a pesca de esporte, de fim de 
semana, em lanchinhas a motor esmaltadas, niqueladas, e impecavelmente coloridas (OLIVEIRA, 1955, p. 212 apud MELLO; VOGEL, 1999, p. 20).

A calma aldeia, o saber-fazer quanto ao sistema tradicional de abertura da barra e o conhecimento da pesca passados por gerações começaram a sentir o reflexo das transformações. Muitos jovens começaram a migrar para outros cantos do Estado, alguns ainda para outras lagoas e outros, para os centros urbanos.

Na década de 1970, outra obra vem pressionar a comunidade: a construção do empreendimento imobiliário da Cidade São Bento da Lagoa. Esse empreendimento resultou em danos ambientais, mortandade de peixes e expulsão de pescadores. Os mais velhos resistiram. Mesmo assim, a redução dos habitantes nas duas décadas seguintes foi enorme: enquanto em 1955 havia aproximadamente 3.600 pessoas, no ano de 1975 havia um total de apenas 1.305 pessoas (MELLO; VOGEL, 2004). Por mobilização da sociedade civil, incluindo pescadores, grupos de técnicos e cientistas, o projeto urbano não pôde ser levado adiante, o que em 1984 resultou na criação da Área de Proteção Ambiental de Maricá. Isso manteve os moradores de Zacarias inseridos, protegendo e "protegidos" nesta Unidade de Conservação, conservando a vegetação de restinga que mantém até o presente a vegetação das dunas primária e secundária.

Após inúmeras obras, conflitos continuaram, principalmente, relacionados às várias transformações da pesca e da atividade local, conforme constatamos em depoimento a seguir:

A barra? A barra é desde o princípio. Desde que existiu Zacarias, existiu a barra. Então era tudo conforme, de antigo. Era tudo por causa dessa barra. No mesmo lugar; sempre aberta no mesmo lugar. [...] Naquela época não tinha a barra de Ponta Negra - o canal que existe hoje em dia, e que uns querem tapar e outros querem abrir aquela confusão! Aqui, era só essa barra. E o pescador vivia por essa barra (Napoleão José de Marins - "Nizinho", pescador da Praia da Zacarias, em 12-11-1983, apud MELLO; VOGEL, 2004, p. 329).

Como uma das pressões mais recentes que a comunidade de Zacarias vem sofrendo, está o mais novo projeto de empreendimento turístico. No ano de 2006, os pescadores da aldeia amanheceram sem compreender o porquê de estarem impedidos de seu direito de ir e vir, ao se depararem com cancela, guarita e com um segurança armado logo na entrada da vila. Este fato acarretou manifestação e derrubada da cancela pelos próprios moradores de Zacarias. Ainda assim, em 2007 ocorreu a implementação de uma longa cerca com arame farpado envolvendo 2,2 milhões $\mathrm{m}^{2}$ da área (Fig. 5).

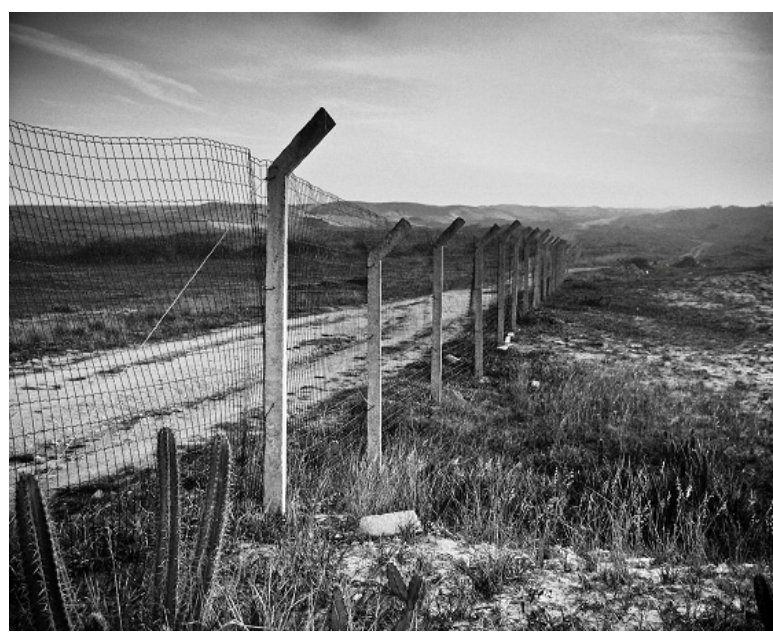

FIGURA 5 - CERCAMENTO DA RESTINGA DE MARICÁ, RJ (BRASIL) PARA FINS DE CONSTRUÇÃO DE RESORT.

Foto: Yasmim Mello, 2008

O cercamento ocorreu em decorrência da compra das restingas, dos cômoros da lagoa e do mar, das praias e, por conseguinte, de tudo que estaria dentro da APA e da faixa de proteção ambiental que margeia o Lago Grande de Maricá por um grupo luso-espanhol. O objetivo para o grupo é o de construir um gigantesco complexo de resorts com investimentos de cerca $\mathrm{R} \$ 8$ bilhões, conforme segue:

Localizada a 40 minutos do centro do Rio de Janeiro. O complexo ecoturístico e residencial aproveitará as vantagens do solo para erguer todas suas unidades com padrão diferencial, protegendo a natureza e inserindo flora e fauna que permita uma qualidade de vida melhor. (Disponível em: <http://www.amathistabrasil.com.br/> $)^{4}$.

${ }^{4}$ Site visitado em 14 de fevereiro de 2009: <http://www.amathistabrasil.com.br/ver_oportunidades.php?id=45>. 
O grupo relata que a região está em constante processo de degradação ambiental e inevitável favelização. Daí a proposta de construção do complexo com 03 resorts, com marina para mais de mil barcos ${ }^{5}$, campos de golfe, 500 quartos, locais para a prática de esportes, sob um discurso de ecoturismo, de atividade ecossustentável. O projeto do resort vem como avanço, trazendo redenção para o atraso. Trata-se de outro caso em nossa história de imposição do modelo desenvolvimentista, inserido no contexto da mercantilização da natureza, que se utiliza do discurso de proteção ambiental como um aspecto da modernização da região.

O povoado hoje, pressionado e com seus pouco mais de 250 habitantes (MELLO; VOGEL, 2004), sofre mais uma vez, agora com a lagoa ainda mais degradada, devido aos inúmeros impactos que vem sofrendo não apenas da região, mas por todo o Estado, uma vez que este ecossistema está integrado em bacia hidrográfica que vai além do município. $\mathrm{O}$ frágil modo de vida acaba sendo um facilitador para que esses moradores incorporem a entrada do turismo como alternativa de sustento. Eles não têm a propriedade da terra, fazem, em parte de seus terrenos, um "puxadinho" para alugar uma casa de veraneio e, por fim, acabam eles, mais uma vez, sendo pressionados e expulsos da sua terra.

Frente às constantes entradas de "estrangeiros do veraneio" como alternativa frente à economia da pesca, observa-se que o local, sobretudo devido à proximidade com os centros urbanos, tem se tornado aos poucos alvo das mazelas urbanas. Esses resistentes pescadores lutam pelo seu direito à terra, ao acesso à natureza e pela garantia de seu território. Demandam a permanência de suas gerações futuras, que ora continuam e retiram força para lutar e viver da pesca, ora deslocam-se para trabalhar em setores como a construção civil e serviços nas cidades.

Cabe aqui uma reflexão: um empreendimento deste porte pode contribuir para a grande redenção do meio ambiente, se fazendo rotular de "ecológico" frente à degradação ambiental? Empreendedores mencionam empregos, preservação da fauna e flora e ecodesenvolvimento. Em resposta, sabemos claramente que está em jogo grande $m a$ rketing verde em um processo contraditório de especulação imobiliária. E o manejo e o conhecimento da população tradicional da comunidade de Zacarias, por meio de sua convivência de séculos com o ambiente e a consequente conservação da restinga, estão sendo dizimados por políticas do passado e do presente. Não serão conservados e sim ameaçados pelos campos de golfe e barcos que irão trafegar livremente pela lagoa. No discurso desenvolvimentista presente, não se considera a pesca artesanal, mas se aposta em atividades de aquicultura no continente. Tampouco, é valorizada a histórica função das populações tradicionais na conservação ambiental.

\section{Conflitos e desafios: conjugação da presença de população tradicional e da conservação ambiental}

Os casos aqui abordados são exemplos dos conflitos e resistências de populações tradicionais frente a projetos globais recorrentes, tanto na região costeira bem como em regiões interioranas por todo o Brasil.

A permanência de populações de pescadores em terras por eles ocupadas secularmente está em questão, assim como o reconhecimento e a delimitação da área de moradia da comunidade, a restrição da ocupação, o uso e a presença nos territórios históricos destas comunidades, bem como a limitação do acesso ao manejo e ao uso da biodiversidade em áreas consideradas de proteção ambiental pelo Estado. A sustentabilidade desse ambiente de restinga e lagoas está ameaçada pelo empreendimento turístico.

As populações tradicionais, como vêm sendo reconhecidas legalmente mais recentemente, são historicamente invisibilizadas, são parte e fruto da questão agrária estrutural ao longo de todo processo de colonização. O projeto dominante de desenvolvimento indicava a incorporação de todos à modernização, entretanto, muitas populações resistem na terra ao longo dos séculos, querendo permanecer e continuar na terra. Assim, questionam e trazem desafios, conforme abordado anteriormente por Pereira (2005), no que diz respeito aos aspectos do legado do desenvolvimento - um conjunto de paradoxos, tais como: questão ambiental, questão agrária e/ou questão socioambiental.

Mota (2007) ressalta que na Comunidade Andorinhas a "tradicionalidade" se tornou um instrumento de garantia de direitos de permanência na terra e de visibilidade positiva no espaço público, de reconhecimento e consideração.

As populações tradicionais são penalizadas e não são reconhecidas pelo seu vasto e antigo conhecimento de convivência e de práticas ligadas à natureza. São distintas

${ }^{5}$ A Marina da Glória no Rio de Janeiro tem capacidade para 600 barcos. 
suas concepções de natureza. Para essas populações, o modo de vida em comunidade e a relação com a natureza não se constitui enquanto dicotomia, visto que há relação de proximidade, de conhecimento, de manejo e cuidado, há um uso conjugado com a dinâmica ecológica do ambiente. Assim, chama-se atenção para existência da referência a um uso sustentável. Por outro lado, as políticas ambientais trazem a concepção de natureza intocada (DIEGUES, 1996), simulada como virgem e selvagem, onde o ser humano pode ser apenas um visitante. Essa concepção vem se tornando dominante e é a concepção base das políticas ambientais, historicamente fruto da visão urbana insatisfeita com as consequências do progresso nas cidades.

Cada vez mais vêm emergindo conflitos socioambientais que têm como eixo a disputa em torno de diferentes concepções e a imposição da concepção de natureza intocada. Essa abordagem vem sendo o "carro chefe" do Estado, bem como dos empreendimentos econômicos. Assim, "aquele que usa", ou seja, o ator social que vive em interdependência estrita com o ambiente é sempre visto como "o sujeito que degrada", ao mesmo tempo em que a degradação resultante do processo de urbanização e seus responsáveis não são considerados. Aliás, o resultado de práticas de desenvolvimento a partir dessa concepção são empreendimentos que afirmam trazer saneamento e garantir o verde-mercadoria e a qualidade de vida para a população - para aqueles poucos incluídos. Há um jogo de escalas (LACOSTE, 1993) no processo de degradação que não é percebido.

Zhouri et al. (2005) bem ressaltam, em seu livro intitulado A insustentável leveza da política ambiental: desenvolvimento e conflitos socioambientais, as bases de conflitos que vêm se configurando a partir das concepções das políticas ambientais. Há conflitos de visões, são diferentes significados e usos. O conflito eclode quando o sentido e a utilização de um espaço ambiental por um determinado grupo são priorizados em detrimento dos usos que outros segmentos sociais possam fazer de seu território e assim assegurar a reprodução do seu modo de vida. Os autores ressaltam a desigualdade social daí advinda:

[...] Os conflitos daí decorrentes denunciam contradições, nas quais as vítimas das injustiças ambientais não só são verdadeiramente excluídas do chamado desenvolvimento, mas assumem todo o ônus resultante (ZHOURI et al., 2005, p. 18).

É importante analisar as situações de tensão e conflito abordadas como conflitos socioambientais. Layrargues (2000) ressalta que o conceito de conflito socioambiental nos permite entender o problema ambiental não apenas pela sua face ecológica, mas também pelo conflito de interesses existente entre os diversos atores sociais em questão. Ascelrad (1995) considera conflitos socioambientais, em síntese, conflitos sociais que têm elementos de natureza como objeto e que expressam relações de tensão entre interesses coletivos/espaços públicos $\mathrm{x}$ interesses privados/tentativas de apropriação de espaços públicos. Envolvem o interesse difuso do livre acesso e usufruto dos serviços da natureza para toda a coletividade.

São muitos os desafios das unidades de conservação instituídas pelo Estado e muitas das vezes com apoio de parte da sociedade civil organizada, constituída com base em uma visão estritamente preservacionista.

Como exemplo disso, no estudo aqui apresentado, observa-se alguns atores sociais ligados à unidade de proteção integral questionando a permanência da população tradicional, como no caso da Comunidade de Andorinhas, no Parque Estadual da Tiririca (Niterói, RJ). Esse comportamento desconsidera que a população teve papel importante na conservação da mata por mais de um século e habita moradias conjugadas com a mata, diferentemente dos condomínios fechados no entorno e na própria Serra da Tiririca, que alteram fortemente o ambiente. No entanto, por serem áreas consideradas urbanizadas e de maior renda, são deixadas fora do conflito, não são questionadas enquanto impacto negativo para o parque. Por outro lado, a Comunidade de Andorinhas somente não foi expulsa porque resistiu e conseguiu o reconhecimento de população tradicional com o apoio de pesquisadores e $\operatorname{advogados}^{6}$, e não o rótulo excludente de invasores e responsáveis pela favelização da área.

Hoje a comunidade está amparada pela Lei Estadual $2.393 / 95^{7}$, que assegura a permanência das populações nativas residentes em unidades de conservação anteriores à criação do parque. Assim, optaram por serem incorporados

\footnotetext{
${ }^{6}$ Da Universidade Federal Fluminense/Nephu, ver Lobão (2002).

${ }^{7}$ Lei de autoria do então deputado estadual Carlos Minc: dispõe sobre a permanência de populações nativas residentes em unidades de conservação do Estado do Rio de Janeiro há mais de 50 anos e garante o direito real de uso das áreas ocupadas, desde que dependam, para sua subsistência, direta e prioritariamente dos ecossistemas locais.
} 
aos limites do parque, entretanto, existem muitas demandas deles para o reconhecimento dos limites da comunidade, bem como para o uso e o acesso à biodiversidade da mata local, que historicamente foi por eles manejada e usada de forma sustentável, visto que se encontra nos dias de hoje em um status de mata conservada. Mota (2009) registrou que o Morro das Andorinhas foi recuperado pela comunidade após os cultivos de café e de cana no século XIX, assim como nos tempos atuais juridicamente foi argumentado que a presença da comunidade no local evitava novas ocupações, desmatamentos, acréscimos das construções já existentes, compatibilizando a natureza com existência da vida humana. Há muitas tensões e restrições em torno do reconhecimento das terras e do território da comunidade. Há pontos de pesca cujo acesso foi cercado por condomínios e que os pescadores não podem mais usar em determinadas épocas do ano.

Vê-se também em uma unidade de uso sustentável o questionamento da permanência da população tradicional de pescadores artesanais de Zacarias na APA Maricá. A população que conviveu e manejou sob bases sustentáveis a lagoa e a vegetação da restinga, que se encontra atualmente bem conservada, vem sendo alijada da área de proteção ambiental, enquanto um resort, que prevê grandes extensões de áreas construídas, vem sendo facilitado e liberado e paradoxalmente ocasionará alterações na restinga e na lagoa, bem como causará degradação ambiental em escala que não permitirá mais a resiliência ambiental ${ }^{8}$ e muito menos o uso sustentável. A implantação da marina projetada prevê dragagem de todo o sistema lacunar, com impactos ambientais previsíveis (MATIAS et al., 2009).

A urbanização trouxe poluição à lagoa de Maricá, que se estende desde a cidade de Maricá. Agora irá trazer lazer para aqueles que reforçam o mito da natureza intocada, a dicotomia ser humano-natureza. Em feriados, usufruem da natureza-mercadoria, pagando para permanecer na área verde do resort, enquanto a população de pescadores é vista como parte de um processo de favelização que ameaça o verde. Não os identificam como mestres da pesca, pescadores seculares, como população tradicional, que ali estavam bem antes deste processo, vivendo sob bases sustentáveis em interação sociedade-natureza.

O movimento ambientalista de Maricá vê com preocupação essa ameaça à APA e à restinga e vem sugerindo a possibilidade de recategorizar a APA como Parque, de uso mais restritivo. Porém, a população de pescadores se manterá sob quais condições numa área de parque? Vem também acontecendo o debate, na Associação dos Pescadores de Zacarias, sobre a possibilidade de a área de moradia e pesca da comunidade se transformar em unidade de uso sustentável na categoria de Reserva Extrativista. Sabe-se que tal categoria de Unidade de Conservação tem a comunidade como gestora, o que é ainda um desafio para a política ambiental estatal, sendo este um dos aspectos que dificulta a implantação desta categoria de UC para outros Estados além do Acre.

$\mathrm{O}$ enfoque reducionista restringe a dimensão da natureza a uma simples variável. Ressaltam Zhouri et al. (2005) que mais uma vez a visão da natureza virgem leva a aumentar os problemas ambientais e a injustiça social. A dicotomia natureza-sociedade leva a natureza a tornar-se uma variável gerida de modo a não atrapalhar o desenvolvimento. Os autores argumentam que há uma dominação do saber técnico-científico que exclui outros saberes:

O olhar técnico compartimentado apenas promove uma adequação ao meio ambiente e da sociedade ao projeto proposto, fazendo com que outros olhares e saberes não enquadrados pelo discurso técnico-científico sejam, assim, excluídos dos processos de classificação e de definição sobre os destinos dos espaços (ZHOURI et al., 2005, p. 17).

Desse modo, faz-se importante uma reflexão aprofundada a partir de um trabalho coletivo de construção do conhecimento na Universidade para além dos muros e dos gabinetes, na busca por se ressaltar a troca, as vivências, as diferentes realidades locais, as diferentes posições, de forma que se reconheçam essas diferentes realidades socioambientais e que as populações sejam incluídas nas decisões políticas. Poder evidenciar que cada um desses elementos forma componentes-chave do conjunto, trazendo desafios no que tange à integração dos eixos ensino-pesquisa-extensão e do papel social da universidade. Santos (2004) sinaliza para o contributo da universidade na definição e na solução coletiva dos problemas sociais, nacionais e globais.

\footnotetext{
${ }^{8}$ Resiliência é a capacidade de um sistema restabelecer o equilíbrio após este ter sido rompido por um certo distúrbio, o que está ligado à capacidade de recuperação relacionada à capacidade de auto-organização do sistema e manutenção da mesma estrutura e funções através do tempo (ODUM, 1985).
} 


\section{Considerações finais}

São muitas as possibilidades em torno da relação entre população e unidades de conservação. Está em jogo um conjunto e a própria vida de pessoas, o domínio da terra, bem como a gestão da natureza e do território. Os aspectos aqui analisados vêm culminando na elitização das áreas verdes e ditas "naturais", tornando a natureza uma mercadoria que, quando vendida, permite que apenas alguns possam consumi-la. Esses processos claramente promovem transformações marcadas por expressiva desigualdade social, expropriação das populações locais e

\section{Referências}

ASCELRAD, Henri; CARVALHO, I.; SCOTTO, G. Conflitos socioambientais no Brasil. v. 1. Rio de Janeiro: Ibase, 1995.

BOFF, Leonardo. Princípio terra: volta à terra como pátria comum. São Paulo: Ática, 1995.

BRAGA, Saturnino. Saneamento da Lagoa de Maricá. Rio de Janeiro: Depto. Nacional de Obras e Saneamento, 1947.

CASTRO, Edna. Território, biodiversidade e saberes de populações tradicionais. In: DIEGUES, A. C. (Org.). Etnoconservação: novos rumos para a proteção da natureza nos trópicos. São Paulo: Hucitec e Nupaub/USP, 2000.

DIEGUES, Antonio Carlos. O mito da natureza intocada. São Paulo: Hucitec, 1996.

Etnoconservação da natureza: enfoques alternativos. In: (Org.). Etnoconservação: novos rumos para a proteção da natureza nos trópicos. São Paulo: Hucitec e Nupaub/ USP, 2000.

. Enciclopédia Caiçara. São Paulo: Hucitec, 2004.

; ARRUDA, Rinaldo S. V. Saberes tradicionais e biodiversidade no Brasil. Brasília: MMA; São Paulo: USP, 2001.

GOMÉZ-POMPA, Arturo; KAUZ, Andrea. Domesticando o mito da natureza selvagem. In: DIEGUES (Org.). Etnoconservação: novos rumos para a proteção da natureza nos trópicos. São Paulo: Hucitec e Nupaub/USP, 2000.

LACOSTE, Yves. A Geografia - isso serve, em primeiro lugar, para fazer a guerra. Campinas: Papirus, 1993.

LAYRARGUES, Philippe Pomier. Educação para gestão ambiental. In: CASTRO, R. S.; LAYRARGUES, P. P.; LOUREI- subalternização à lógica de dominação. A partir de uma visão preservacionista restrita de unidade de conservação, reproduz-se necessariamente a noção de separação do ser humano da natureza, reforça-se o conceito de natureza virgem intocada e desconsideram-se outras concepções existentes, onde natureza/cultura estão interligadas enquanto totalidade e a partir de onde existem possibilidades para convivência entre natureza/ambiente "protegido" e seres humanos. A partir da crise ambiental e da compreensão da crise de paradigma que aí se esconde, reconhecemos novas possibilidades de construção do conhecimento na interface ciência e sociedade, ciência e população tradicional, de onde se apontam novos rumos para a política ambiental.

RO, C. F. B. (Orgs.). Sociedade e meio ambiente: a educação ambiental em debate. São Paulo: Cortez, 2000.

LEITE, Eliana. Morar lá em cima é tudo. Niterói: Associação da Comunidade Tradicional do Morro das Andorinhas, 2003.

LIMONAD, Ester. "Yes Nós Temos Bananas!" Praias, condomínios fechados, resorts e problemas socioambientais. GEOgraphia, UFF, Ano IX, n. 17, p. 63-88, 2007.

LITTLE, Paul. Territórios sociais e povos tradicionais no Brasil: por uma antropologia da territorialidade. Brasília: ICS - UNB - Série Antropologia, 2002.

LOBÃO, Ronaldo J. S. Pondo a mesa para o inimigo ou demoliu minha casa e sentou à minha mesa para comer minha comida. In: COLÓQUIO DA REDE INTERDISCIPLINAR DE ESTUDOS COMPARATIVOS: DIREITO, JUSTIÇA E SEGURANÇA PÚBLICA (RIEC), 1., Rio de Janeiro, 2002. Anais... Rio de Janeiro: IFCS/UFRJ, 2002.

Cosmologias políticas do neocolonialismo: como uma política pública pode se tornar uma política de ressentimento. Tese (Doutorado em Ciências Sociais/PPGAS) - UnB, Instituto de Ciências Sociais. Brasília, 2007.

MATIAS, M. L.; SILVA, M. C. C.; LOUREIRO, D. S.; CORREA, G. S.; FREIRE, D. G. Disputa por território na Área de Proteção Ambiental de Maricá - Rio de Janeiro. In: ENCONTRO DE GEÓGRAFOS DE AMERICA LATINA, 12., Montevideo, 2009. Anais... Montevideo: Universidad de La Republica, 2009.

MEIRELES, Antonio Jeovah de Andrade. Danos socioambientais na zona costeira cearense. In: HERCULANO, S.; 
PEREIRA, M. C. B.; MELLO, Y. R. Projetos globais e resistências locais: pescadores artesanais e...

PACHECO, T. (Orgs.). Racismo ambiental. Rio de Janeiro: Lactta/UFF \& BSD/Fase, 2006.

MELLO, Marco Antônio da Silva; VOGEL, Arno. A fisiocracia agreste: manejo e gestão ambiental. In: ENCONTRO REGIONAL DA ABA NORTE E NORDESTE, 6., 1999, Belém. Anais... Belém-PA, 1999.

Gente das areias: história, meio ambiente e sociedade no litoral brasileiro (Maricá-RJ, 1975-1995). Niterói: EdUFF, 2004.

MELLO, Yasmim Ribeiro; PEREIRA, Mônica Cox de Britto. Dialogando ensino, pesquisa extensão na monitoria: integração e construção do conhecimento ecológico a partir do diálogo de saberes. In: SEMANA DE MONITORIA, 11., 2008, Niterói. Anais... Niterói, 2008.

MENDES, Andréa M.; SARAIVA, Joana M. Saia de sua casa porque o meio ambiente vem aí: um relato sobre o conflito ambiental no morro das andorinhas. Violência e processos institucionais de administração de conflitos. In: REUNIÃO DE ANTROPOLOGIA DO MERCOSUL, 4., Curitiba, 2001. Anais... Curitiba, 2001.

MOTA, Fabio Reis. Dilemas de uma cidadania à brasileira: dimensão da consideração na promoção de humanos direitos. In: CUNHA, Neiva Vieira da (Org.). Direitos negados. v. 1. Rio de Janeiro: Booklink, 2004.

Quando a cidade vira meio ambiente: notas antropológicas sobre conflitos ambientais no Brasil. FIRST INTERNATIONAL CONFERENCE OF YOUNG URBAN RESEARCHERS (FICYUrb), 1 ${ }^{\text {st }}$., Lisboa, 2007. Anais... Lisboa, 2007.

Cidadãos em toda a parte ou cidadãos à parte? Demandas de reconhecimento de direitos no Brasil e na
França. Tese (Doutorado em Antropologia/PPGA) - UFF. Niterói, 2009.

O GLOBO. Os novos resorts do litoral - Empreendimentos de alto luxo podem definir novo modelo de ocupação de áreas verdes. Edição: 10/06/2007. Impresso: 9/06/2007, p. 1.8.

ODUM, Eugene. Ecologia. Rio de Janeiro: Interamericana, 1985.

PEREIRA, Mônica Cox de Britto. Desenvolvimento e meio ambiente: o todo é maior que a soma das partes. Revista Plurais, UEG, v. 1, n. 2, p. 265-272, 2005.

; SILVA, Helio Ricardo; CARAMASCHI, Ulisses. Frugivory and seed dispersal by Hyla truncata, a neotropical treefog. Copeia, v. 3, p. 781-783, 1989.

POSEY, Darrel. Indigenous Knowledge and Development: an ideological bridge to the future. Ciência e Cultura, v. 35, p. 877-894, 1983.

SANTOS, Boaventura de Souza. A universidade no século $X X I$ : para uma reforma democrática e emancipatória da universidade. São Paulo: Cortez, 2004.

SIMON, Alba Valéria Santos. Conflitos na conservação da natureza: o caso do Parque Estadual da Serra da Tiririca, Niterói. Dissertação (Mestrado em Ciências Ambientais/PGCA) - UFF. Niterói, RJ, 2003.

SNUC. Sistema Nacional de Unidades de Conservação da Natureza. Lei n. 9.985, de 18 de julho de 2000; decreto n. 4.340, de 22 de agosto de 2002. 2. ed. aum. Brasília: MMA/SBF, 2002.

ZHOURI, Andrea; LASCHEFSKI, Klemens; PEREIRA, Doralice. (Orgs.). A insustentável leveza da política ambiental: desenvolvimento e conflitos socioambientais. Belo Horizonte: Autêntica, 2005.

Recebido em maio de 2011.

Aceito em setembro de 2011. Publicado em dezembro de 2011. 